\title{
Modelo logístico para determinar la velocidad máxima y tiempo de fermentación láctica en residuos sólidos de pescado
}

\section{Logistical model to determine maximum speed and lactic fermentation time in solid fish residues}

iD 'Víctor M. Terry Calderón (iD ' José Candela Díaz

Universidad Le Cordon Bleu. Lima, Perú.

Universidad Nacional Federico Villareal. Lima, Perú. ${ }^{2}$

\section{Resumen}

En el presente trabajo de investigación se plantea dentro de la transformación de los residuos sólidos provenientes de las mesas de fileteo de pescado, la vía fermentación láctica, utilizar el Modelo Logístico y de su primera derivada, para determinar la velocidad máxima (Vmax) de producción dentro del proceso y tiempo del proceso. Se aplicaron los parámetros tecnológicos de concentración de sustrato (S), inóculo (MO), temperatura ( $\mathrm{T}$ ) y pH. En este este primer estadio se aplicaron los siguientes parámetros: Concentración de sustrato: melaza $10 \%$, residuos sólidos: $87,0 \%$, el inoculo compuesto de bacterias lácticas (3,0 \%), temperatura de trabajo: $30^{\circ} \mathrm{C}, \mathrm{pH}$ inicial 6,80, pH final 3,37 como promedio en 96 horas. Se obtuvo un rendimiento del $113 \%$ y una velocidad máxima en un rango de 20 a 40 horas. El conocimiento de la velocidad máxima (Vmax) de generación de ácido láctico y el punto final del proceso de biotransformación está en relación directa con la temperatura. Palabras clave: Fermentación láctica, residuos sólidos de pescado, modelo logístico, velocidad máxima de fermentación (Vmax).

\section{Abstract}

In this research, work arises within the transformation of solid waste from fish fillet tables, lactic fermentation, use the Logistic Model and its first derivative to determine the maximum speed (Vmax) of production within the process and time of the process. Technological parameters of substrate concentration (S), inoculum $(\mathrm{MO})$, temperature $(\mathrm{T})$ and $\mathrm{pH}$ were applied. In this first stage, the following

Recibido: Junio 2020

Aceptado: Setiembre 2020 parameters were applied: Substrate concentration: 10\% lylasses, solid residues: $87.0 \%$, the inoculum composed of lactic bacteria (3.0\%), Working temperature: $30{ }^{\circ} \mathrm{C}$, initial pH 6.80, final pH 3.37 on average in 96 hours. A performance of 113\% and a maximum speed were achieved in a range of 20 to 40 hours. Knowledge of the maximum speed ( $V \max$ ) of lactic acid generation and the endpoint of the biotransformation process is directly relative to temperature. 
Keywords: Lactic fermentation, solid fish residues, logistic model, maximum fermentation speed (Vmax)

\section{INTRODUCCION}

Los denominados residuos sólidos de pescado, en partículas los crudos, provienen mayormente de las mesas fileteadoras de pescado (procedentes de fábricas o de mercados), los cuales constituyen un problema de carácter ambiental (Spanopoulos-Hernandez, 2010). por los malos olores y la contaminación. FAO. (2019). Otras formas de residuos sólidos como vegetales, pueden utilizarse con los residuos de pescado o también solos. Gil-Horán (2008).

Según Santos, C. (2005), una forma de mitigar estos residuos, es la fermentación láctica de los mismos, usando como inóculo las bacterias lactobacilos, como fuente de carbón la melaza con su gran aporte de azúcares; asi mismo, se considera la temperatura entre 28 a $35^{\circ} \mathrm{C}$ (FAO.,2019). El objetivo del trabajo es aplicar la ecuación logística y su primera derivada que interprete el proceso de fermentación; así como, la velocidad máxima de producción y el tiempo de fermentación que deberá tener el material.

\section{MATERIALES Y METODOS}

\section{Ámbito temporal y espacial del estudio}

La investigación se efectuó en los laboratorios de la Universidad Le Cordon Bleu, La investigación realizada es cuantitativa, y basada en los ensayos experimentales de causa efecto se desarrolló entre abril y julio 2019.

\section{Muestra:}

Fueron colectados residuos sólidos de la mesa de fileteo del mercado de Surquillo N 2, mayormente residuos de jurel, transportadas al laboratorio en contenedores térmicos a $0^{\circ} \mathrm{C}$. Usando un modelo aleatorio simple para una población infinita se determinó el tamaño de la muestra a través de la ecuación:

$$
n=\frac{z^{2} \cdot p \cdot q}{d^{2}}
$$

n: tamaño de la muestra.

z: margen de confiabilidad a un $95 \%$ de significancia: 1,96,

d: error definido en $10 \%$,

p: nivel de confianza $95 \%$,

q: margen del error que no ocurra $5 \%$

Se obtuvo como muestra final 22 residuos sólidos.

\section{Diseño de la investigación}

Primera etapa: Relación de peso de residuos sólidos y el pescado entero, lo cual daría la proporción de residuos/materia prima; esta etapa comprende la determinación de composición química proximal: \% de proteínas, \% cenizas, \% humedad, \% grasa y pH.

\section{Segunda etapa: aplicación de paráme- tros tecnológicos:}

Concentración de sustrato (S), el sustrato está conformado por melaza derivada de la caña de azúcar y como varía esta en el tiempo de fermentación. Concentración de sustrato de $5 \%$ a $12 \%$ en relación al peso de los residuos sólidos.

\section{Concentración de microorganismos}

(N), son lactobacilos La concentración inicial de microrganismo representa el $3 \%$ del paso del residuo. 


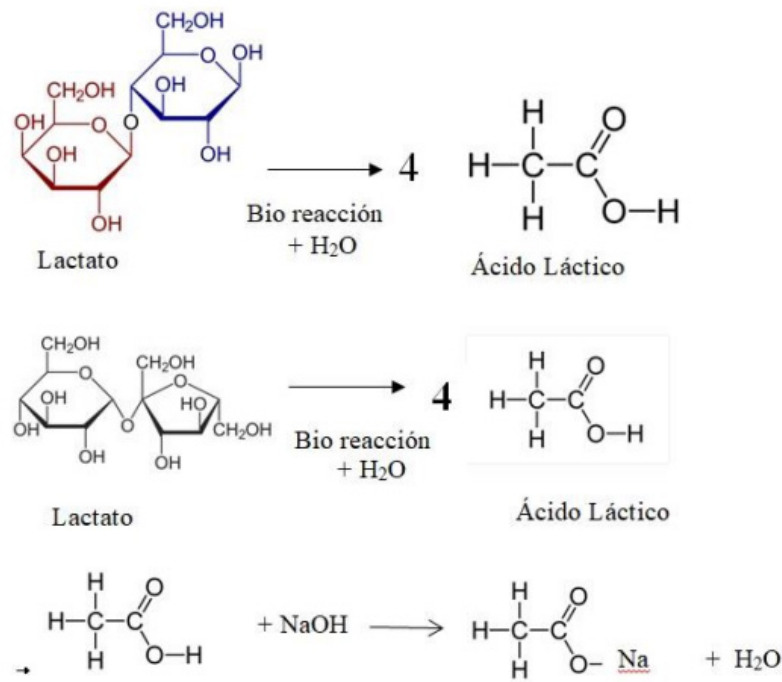

Figura 1. Reacciones estequiometrias involucradas en la generación de ácido láctico y su neutralización

\section{Generación de Producto (P):}

Monitoreo de la generación de ácido láctico por biotransformación de los azúcares Temperatura de proceso:

Para este tipo de fermentación se debe programar a $30^{\circ} \mathrm{C}$

\section{Tercera etapa: Procedimientos}

Teniendo los valores de los parámetros derivados de la fermentación láctica, preparar los ensayos debidos

Diagrama de flujo de la operación de fermentación láctica, se inicia con el ingreso de residuos sólidos orgánicos provenientes de los residuos de pescado., terminando en producto final

\section{Diseño experimental}

El diseño experimental se basó en un diseño en bloques completo al azar (DBCA).

\section{Tratamientos}

Para efectos de la presente investigación se consideró tres ensayos de muestras diferentes tomadas en días alternos. Los cuales fueron evaluados por incremento de la acidez (\% de ácido láctico)

Composición física de los residuos sólidos Para determinar la composición física de los residuos sólidos se tomaron tres muestras en tiempos diferentes.

\section{Tabla 1}

\section{Composición física de los residuos sólidos}

\begin{tabular}{ll}
\hline Elementos & $\mathbf{( \% )}$ \\
\hline Cabezas & 20,60 \\
Vísceras & 5,10 \\
Cola y aletas & 6.20 \\
Cuerpo & 68.00 \\
\hline
\end{tabular}




\section{Unidad experimental}

Está unidad estuvo conformada por:

- Residuos sólidos debidamente esteriliza$\operatorname{dos}(87 \%)$

- El uso de melaza como fuente de carbono $(10 \%)$

- Inóculo de bacterias lactobacilos (3\%)

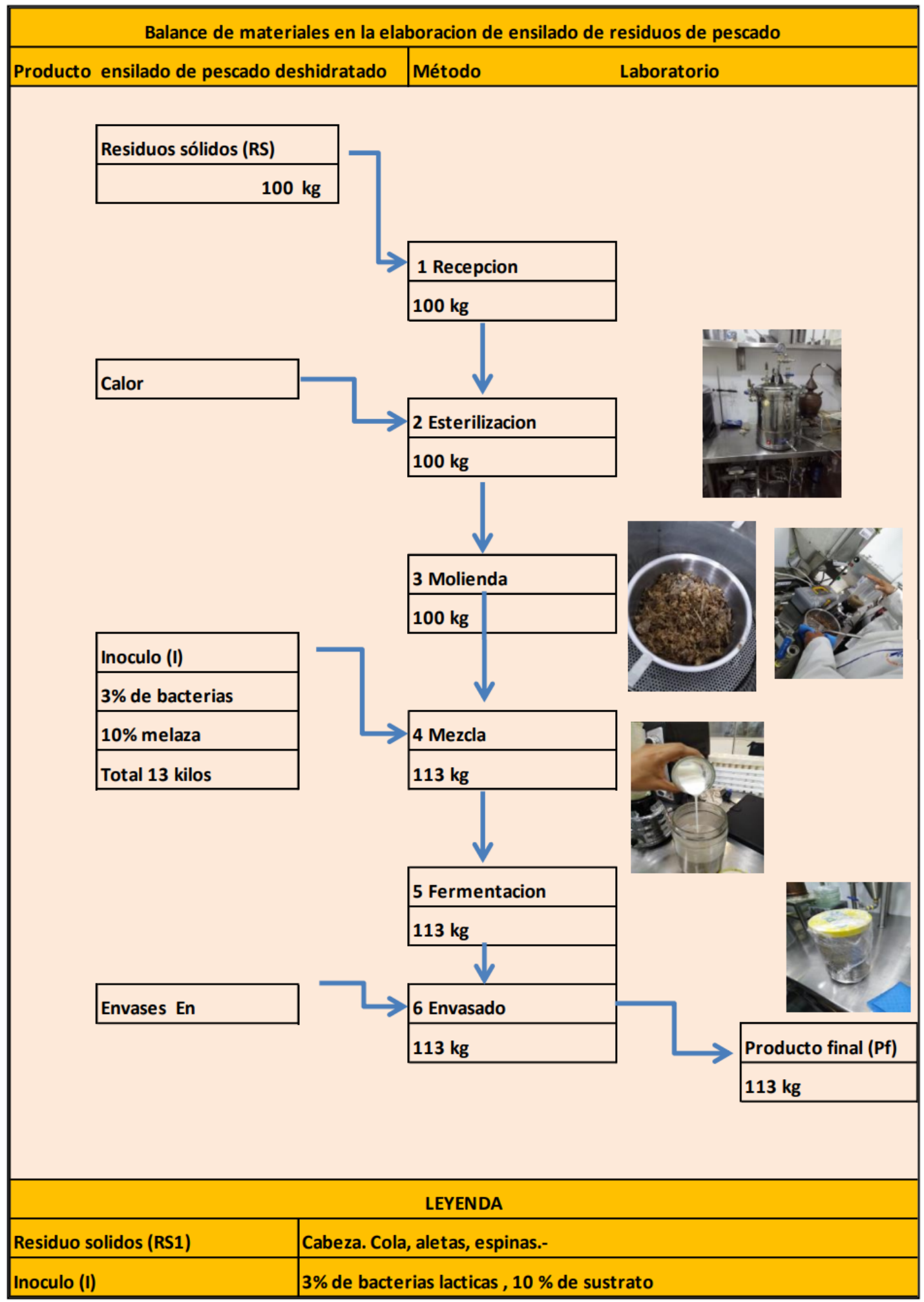

Figura 2. Diagrama de flujo de la operación de ensilado 


\section{Tabla 2}

Descripción del proceso de fermentación

\begin{tabular}{|c|c|c|c|}
\hline \multicolumn{4}{|c|}{ DESCRIPCIÓN DEL PROCESO DE FERMENTACIÓN } \\
\hline & Operación & Descripción & Control \\
\hline 1 & Recepción & El material fue obtenido de las mesas de fileteadores & Siempre en frío \\
\hline 2 & Esterilización & $\begin{array}{l}\text { El residuo sólido compuesto de víscera, cabeza, } \\
\text { colas, escamas y aletas, se esterilizaron para } \\
\text { eliminar las bacterias y evitar la competencia con } \\
\text { los lactobacilos }\end{array}$ & $\begin{array}{l}\text { Esterilizar a } \\
115^{\circ} \mathrm{C} \text { x } 30 \mathrm{~min}\end{array}$ \\
\hline 3 & Molienda & $\begin{array}{l}\text { Terminada la esterilización el material debe ser } \\
\text { molido para favorecer la fermentación }\end{array}$ & $\begin{array}{l}\text { Mediante } \\
\text { licuadora }\end{array}$ \\
\hline 4 & Fermentación & $\begin{array}{l}\text { Adición de } 3 \% \text { de inóculo, } 10 \% \text { de sustrato y } \\
87 \% \text { de residuos sólidos esterilizados y molidos }\end{array}$ & $\begin{array}{l}\text { Peso de } \\
\text { componentes }\end{array}$ \\
\hline 5 & Envasado & Colocarlo en bolsas flexibles & Envases \\
\hline
\end{tabular}

Variables de respuestas al proceso de fermentación

Determinación del contenido de ácido lácti$\mathrm{CO}$, por titulación con $\mathrm{NaOH} 0,1 \mathrm{~N}$

\section{Fermentación láctica de los residuos sólidos}

Los residuos sólidos, debidamente esterilizados y molidos se colocaron en balones de 2 litros donde se incluía el inóculo, de acuerdo a lo indicado anteriormente, se consideraron tres pruebas de fermentación láctica.

\section{Variación del ácido láctico en el ensilado y su evaluación estadística}

Para efectos de los ensayos experimentales se procedió a colocar los balones en un sistema de calefacción a $30^{\circ} \mathrm{C}$ por espacio de 96 horas y se programaron tres ensayos experimentales para observar el incremento de acidez durante este lapso de tiempo como se muestra en la Tabla 3

\section{Tabla 3}

\section{Incremento de la acidez en el ensilado}

\begin{tabular}{cccc}
\hline & Ensayo 1 & Ensayo 2 & Ensayo 3 \\
\hline Tiempo (t) & Acidez & Acidez & Acidez \\
\hline 0 & 0.6 & 0.72 & 0.68 \\
24 & 1.3 & 1.35 & 1.32 \\
48 & 1.9 & 1.89 & 1.84 \\
72 & 2 & 1.94 & 1.95 \\
96 & 2.4 & 2.3 & 2.35 \\
\hline Valores expresados en porcentajes (\%) & &
\end{tabular}

Análisis estadístico

Se utilizó el programa EXCEL y se aplicó el
ANOVA y la prueba de Fisher con un nivel de significancia estadístico p: $<0.05$ 


\section{RESULTADOS}

Según el ANOVA se obtuvieron los siguientes resultados

La Prueba de Fischer ( $F$ )

Para los tratamientos (ensayos) el valor F(critico $)=4,46$ el $F($ experimental) $=0,896$. Luego, se concluye que el valor $\mathrm{F}$ (critico) $>\mathrm{F}$ (experimental), por lo tanto, no existen diferencias significativas entre los tratamientos (ensayos).

\section{Modelo de la ecuación logística y su pri- mera derivada}

Es una ecuación denominada también de pseudo orden uno, por la teoría de la cinética química.

$$
P=\frac{P_{f}}{1+a \cdot e^{-k . t}}
$$

P: producción de ácido láctico (\%) en función del tiempo

Pf: producción asintótica de ácido láctico.

k: constante de velocidad de biorreacción

t: tiempo de bioreacción

a: constante sin valor físico químico

Linealizando la ecuación para poder realizar el respectivo análisis de regresión

$$
\begin{aligned}
& \frac{P}{P_{f}}=\frac{1}{1+a \cdot e^{-k . t}} \\
& \frac{P_{f}}{P}=1+a \cdot e^{-k \cdot t} \\
& \frac{P_{f}}{P}-1=a \cdot e^{-k \cdot t} \\
& \operatorname{Ln}\left(\frac{P_{f}}{P}-1\right)=\operatorname{Ln}(a)-k(t)
\end{aligned}
$$

La primera derivada de la ecuación logística

$$
\frac{d(P)}{d t}=\frac{b \cdot e^{-k(t)}}{\left(a \cdot e^{-k \cdot(t)}+1\right)^{2}}
$$

Por análisis de regresión se obtienen los parámetros de la ecuación como son: a (intercepto con el eje de y) y k (pendiente de la ecuación linealizada)

\section{Aplicación del modelo logístico}

A partir de la Tabla 3 se realizaron los análisis de cada ensayo

\section{Análisis del ensayo 1}

Para el ensayo 1, se graficó P1 en función del tiempo (t) y que se presenta en la Figura 3, donde se observa la evolución del contenido de ácido láctico.

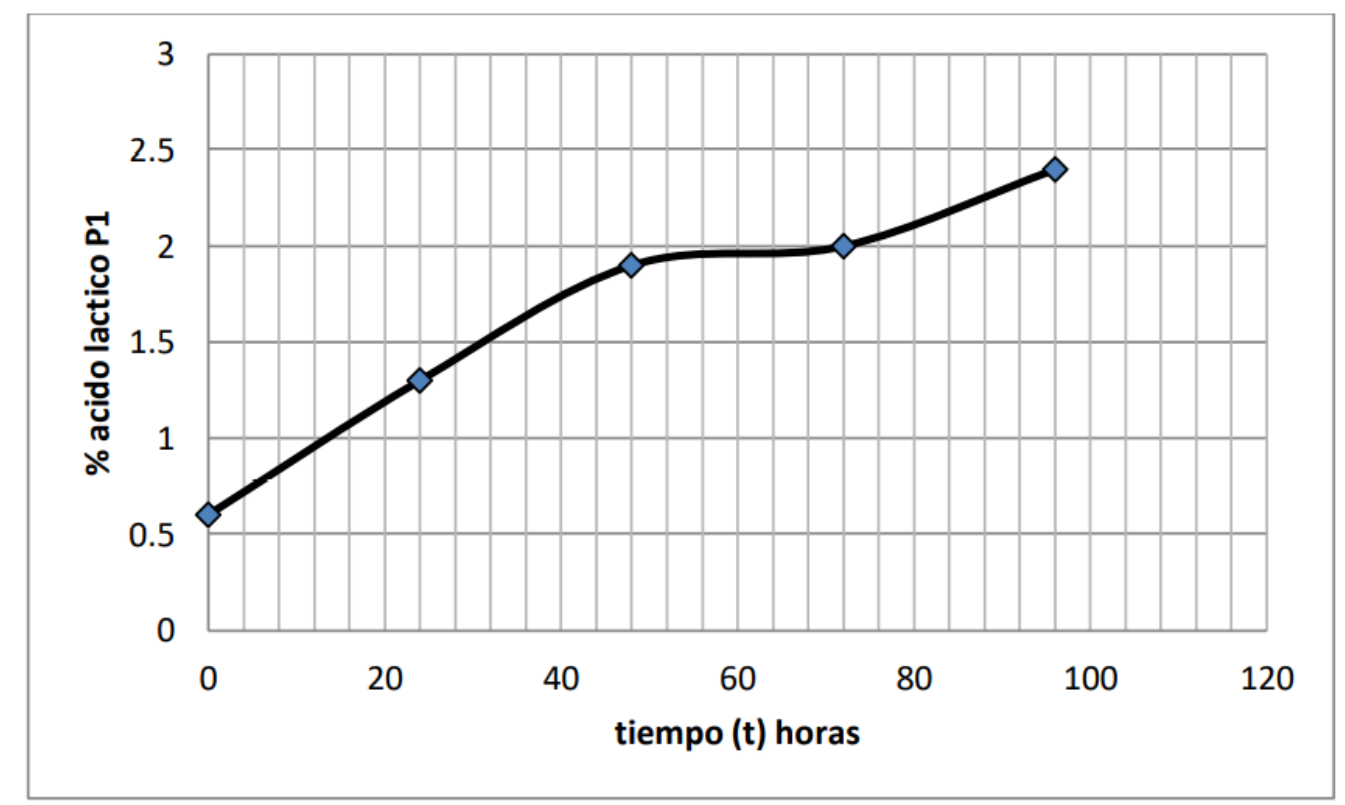

Figura 3. Producción (P1) de ácido láctico en función del tiempo (t) 
Aplicando el análisis de regresión de la curva linealizada se obtuvo los parámetros a=2,437, $k=0,039$ y $R=-0,969$, lo que resulta una ecuación:

$P 1=\frac{2,4}{1+2,437 \cdot \mathrm{e}^{-0,039 \cdot(t)}}$ donde su primera derivada:
$\frac{d(P 1)}{d t}=\frac{0,2281 \cdot e^{-0,039 \cdot(t)}}{\left(2,437 e^{-0,039(t)}+1\right)^{2}}$ Dándole valores y grafi cando $\frac{d(P 1)}{d t}$ en función del tiempo se obtiene la siguiente tabla

\section{Tabla 4}

Velocidad de transformación del sustrato a ácido láctico en el ensayo 1

\begin{tabular}{cc}
\hline Tiempo $(\mathrm{t}) \mathrm{h}$ & $\mathrm{d}(\mathrm{P} 1) / \mathrm{dt}$ \\
\hline 0 & 0,019 \\
10 & 0,022 \\
20 & 0,023 \\
30 & 0,023 \\
40 & 0,021 \\
50 & 0,018 \\
60 & 0,014 \\
70 & 0011 \\
80 & 0,0082 \\
\hline
\end{tabular}

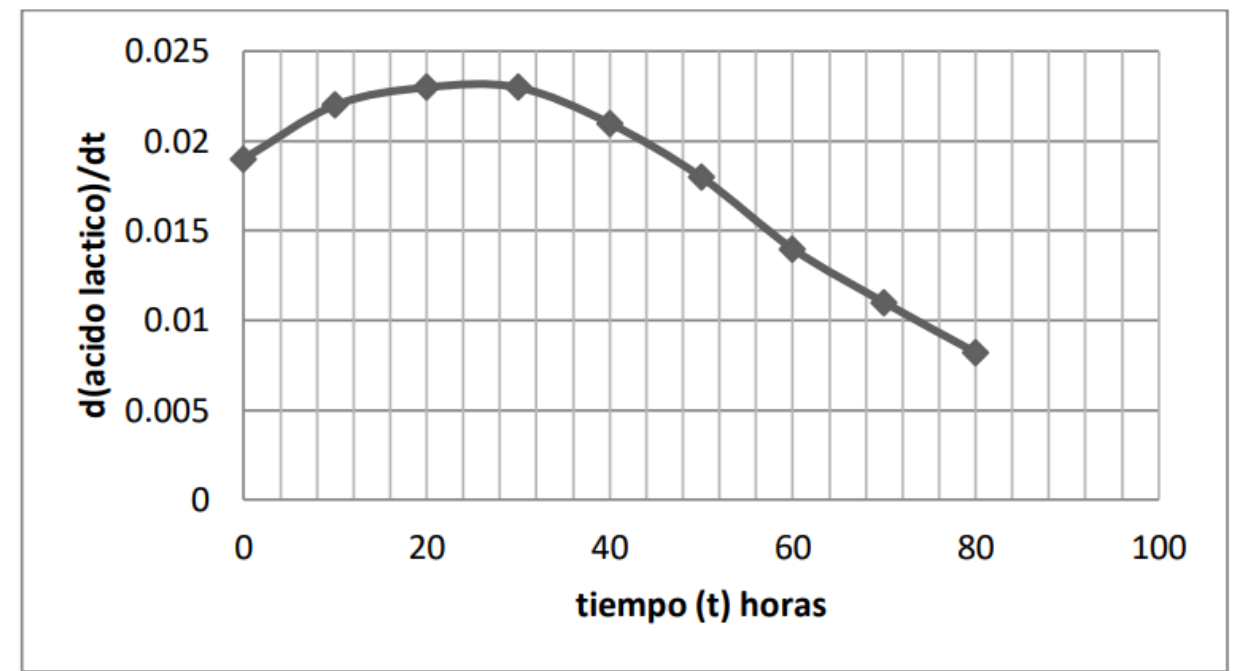

Figura 4. Velocidad de producción de ácido láctico en función del tiempo 


\section{Análisis del ensayo 2}

Para el ensayo 2 se graficó P2 en función del tiempo (t) y que se presenta en la Figura 5,

donde se observa cómo evoluciona el contenido de ácido láctico.

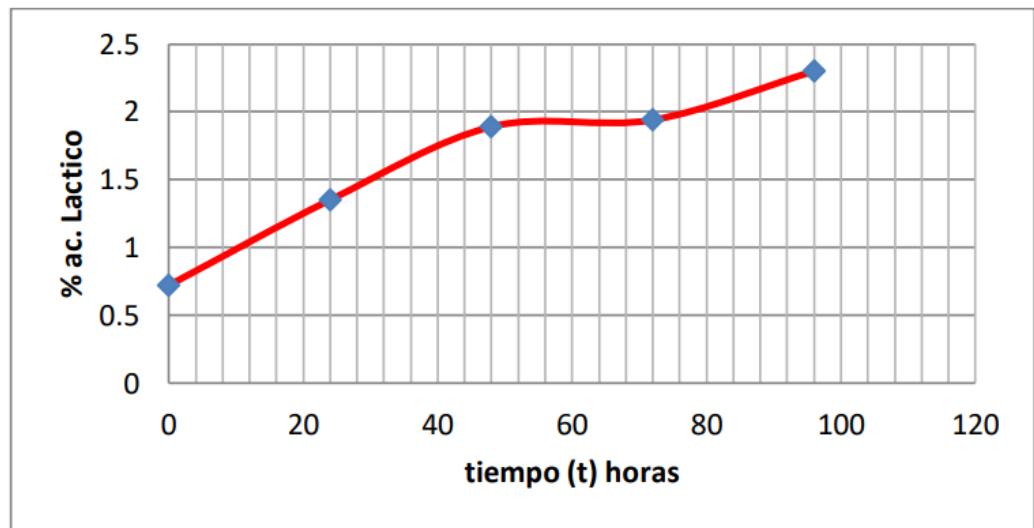

Figura 5. Producción (P2) de ácido láctico en función del tiempo (t)

Aplicando el análisis de regresión de la curva linealizada se obtiene los parámetros a $=1,811$, $k=0,036$ y $R=-0,962$, lo que resulta la siguiente ecuación:

$P 2=\frac{2,30}{1+1,811 \cdot \mathrm{e}^{-0,036 \cdot(t)}}$ donde su primera derivada:
$\frac{d(P 2)}{d t}=\frac{0,1499 \cdot e^{-0,036 \cdot(t)}}{\left(1,811 e^{-0,036(t)}+1\right)^{2}}$ Dándole valores y grafi cando $\frac{d(P 2)}{d t}$ en función del tiempo se obtiene la siguiente tabla

\section{Tabla 5}

Velocidad de transformación del sustrato a ácido láctico en el ensayo 2

\begin{tabular}{ll}
\hline tiempo $(\mathrm{t}) \mathrm{h}$ & $\mathrm{d}(\mathrm{P} 2) / \mathrm{dt}$ \\
\hline 0 & 0,019 \\
10 & 0,020 \\
20 & 0,021 \\
30 & 0,020 \\
40 & 0,017 \\
50 & 0,015 \\
60 & 0,012 \\
70 & 0,009 \\
80 & 0,009 \\
\hline
\end{tabular}


Así mismo, se presenta el gráfico de la velocidad de formación del ácido láctico

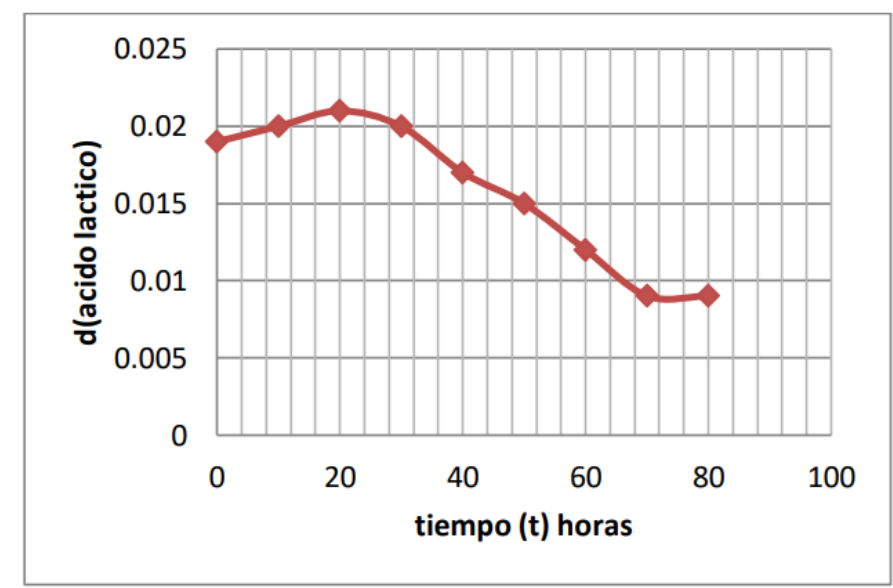

Figura 6. Velocidad de producción de ácido láctico en función del tiempo

\section{Análisis del ensayo 3}

Para el ensayo 3, se graficó P3 en función del tiempo (t) y que se presenta en la Figura 7,

donde se observa cómo evoluciona el contenido de ácido láctico.

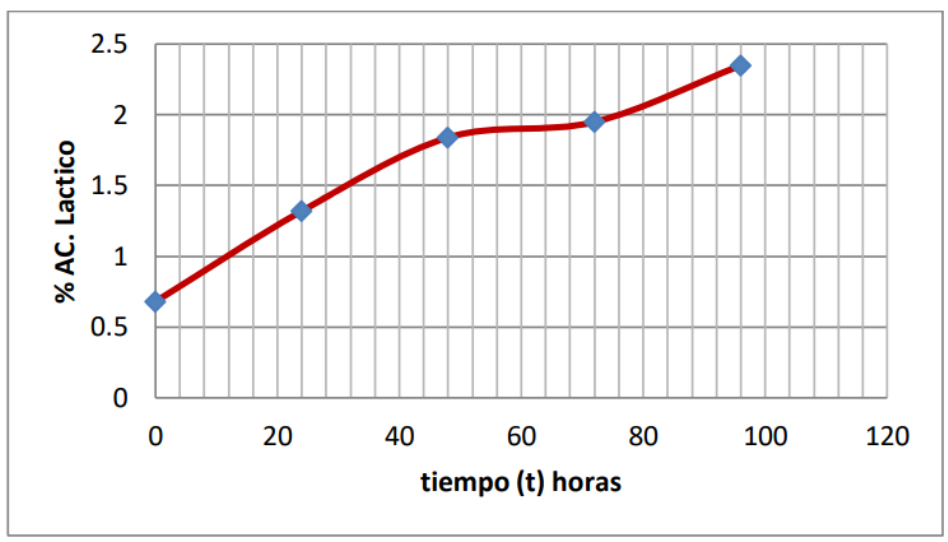

Figura 7. Producción (P3) de ácido láctico en función del tiempo (t)

Aplicando el análisis de regresión de la curva linealizada se obtiene los parámetrosa $=2,437$, $k=0,039$ y $R=-0,969$, lo que resulta la siguiente ecuación:

$P 3=\frac{2,35}{1+2,051 \cdot \mathrm{e}^{-0,035 \cdot(t)}}$ donde su primera derivada:
$\frac{d(P 3)}{d t}=\frac{0,16869 \cdot e^{-0,035 \cdot(t)}}{\left(2,051 e^{-0,035(t)}+1\right)^{2}}$ Dándole valores y grafi cando $\frac{d(P 3)}{d t}$ en función del tiempo se obtuvo la siguiente tabla 
Tabla 6

Velocidad de transformación del sustrato a ácido láctico en el ensayo 3

\begin{tabular}{cc}
\hline tiempo $(\mathrm{t}) \mathrm{h}$ & $\mathrm{d}(\mathrm{P} 3) / \mathrm{dt}$ \\
\hline 0 & 0,018 \\
10 & 0,020 \\
20 & 0,021 \\
30 & 0,020 \\
40 & 0,018 \\
50 & 0,016 \\
60 & 0,013 \\
70 & 0,011 \\
80 & 0,008 \\
\hline
\end{tabular}

Se presenta el gráfico de la velocidad de formación del ácido láctico en la Figura 8

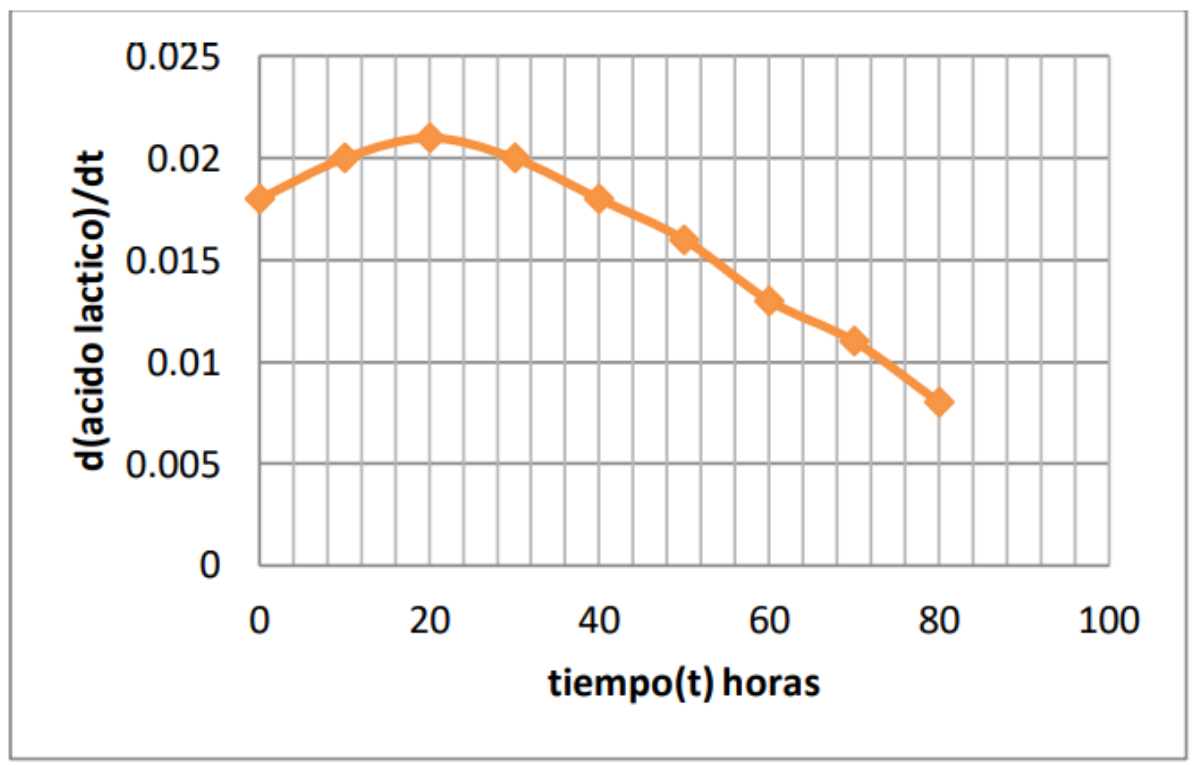

Figura 8. Velocidades de producción de ácido láctico en función del tiempo

Realizando la simulación en base a los datos encontrados se determinó el promedio de los tres ensayos y se obtuvo lo siguiente: 


\section{Tabla 7}

Valores promedio de acidez de los ensayos 1,2, y 3

\begin{tabular}{ccccc}
\hline & Ensayo 1 & Ensayo 2 & Ensayo 3 & $\mathrm{X}$ \\
\hline Tiempo $(\mathrm{t}) \mathrm{h}$ & acidez & acidez & acidez & acidez \\
\hline 0 & 0,6 & 0,72 & 0,68 & 0,67 \\
24 & 1,3 & 1,35 & 1,32 & 1,32 \\
48 & 1,9 & 1,89 & 1,84 & 1,88 \\
72 & 2,0 & 1,94 & 1,95 & 1,96 \\
96 & 2,4 & 2,30 & 2,35 & 2,35 \\
\hline
\end{tabular}

Valores expresados en porcentajes (\%)

$\mathrm{X}$ : promedio del \% de acidez de los tres ensayos.

Efectuando un análisis de regresión y aplicando el modelo logístico se obtuvo la siguiente expresión:

$$
P n=\frac{2,35}{1+2,072 \cdot^{-0.036 \cdot(t)}}
$$

Y donde la primera derivada de la función $(P n)$ es:

$$
\frac{d(P n)}{d t}=\frac{0,1752 \cdot e^{-0,036(t)}}{\left(2,072 \cdot e^{-0.036(t)}+1\right)^{2}}
$$

Donde (t) es el tiempo Desarrollando la ecuación se obtuvo la siguiente tabla

\section{Tabla 8}

Velocidad de promedio de formación de ácido láctico (dPn/dt) y ácido láctico formado $(P)$ en función del tiempo

\begin{tabular}{ccc}
\hline Tiempo (t)horas & $(\mathrm{d}(\mathrm{Pp}) / \mathrm{dt}) 100$ & Pn \\
\hline 0 & 1.9 & 0.765 \\
10 & 2.1 & 0.961 \\
20 & 2.1 & 1.17 \\
30 & 2.1 & 1.379 \\
40 & 1.9 & 1.576 \\
50 & 1.6 & 1.75 \\
60 & 1.3 & 1.897 \\
70 & 1.1 & 2.014 \\
80 & 0.7 & 2.105
\end{tabular}

Pn: valores promedios de los tres ensayos (\% de ácido cítrico)

(dPp/dt)x100: velocidad de producción de ácido láctico multiplicado por 100 
En la Figura 9, se observa como la velocidad máxima de formación está entre las 20 y 40 horas

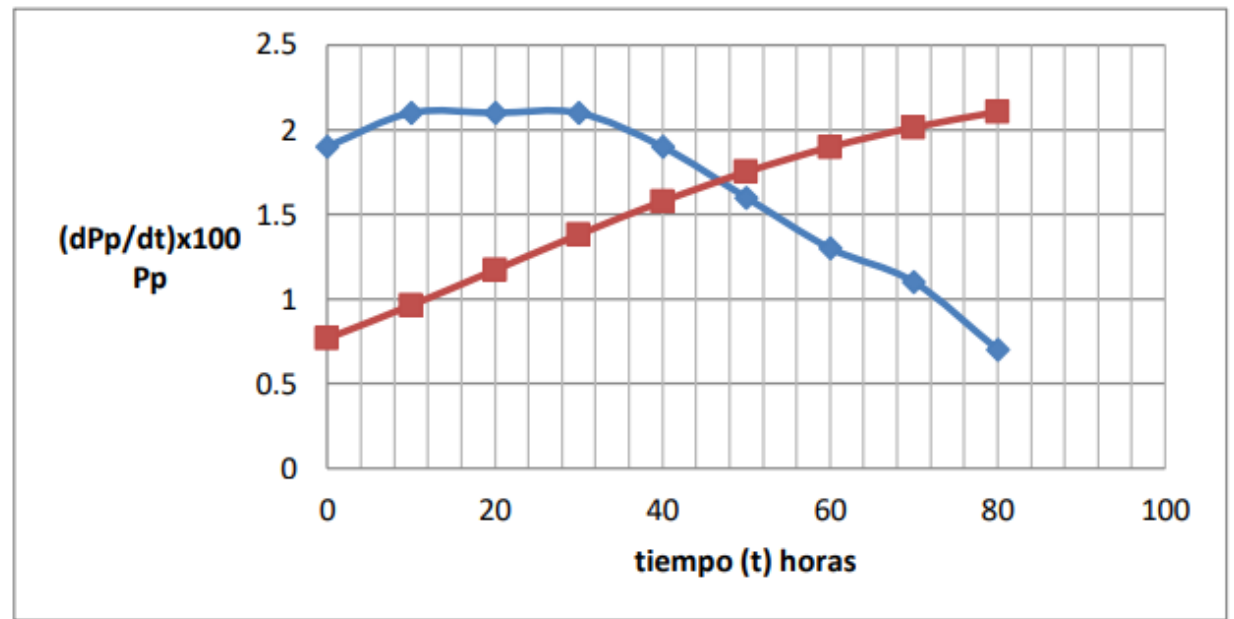

Línea azul: $(\mathrm{dPp} / \mathrm{dt})$

Línea roja: generación de ácido láctico $(\mathrm{P})$

Figura 9. Velocidad de formación del ácido láctico

\section{Variación del pH durante el proceso}

En la siguiente tabla se observa el descenso del pH durante el proceso de fermentación

\section{Tabla 9}

Valores de la evaluación del pH en los ensayos y del promedio del pH

\begin{tabular}{ccccc}
\cline { 2 - 5 } & Ensayo 1 & Ensayo 2 & Ensayo 3 & Promedio \\
\hline tiempo $(\mathrm{t}) \mathrm{h}$ & $\mathrm{pH}$ & $\mathrm{pH}$ & $\mathrm{pH}$ & $\mathrm{pH}$ \\
\hline 0 & 6,81 & 6,82 & 6,78 & 6,80 \\
24 & 5,41 &, 5.49 & 5,49 & 4,46 \\
48 & 4,40 & 4,42 & 4,44 & 4,42 \\
72 & 3,50 & 3,60 & 3,30 & 3,47 \\
96 & 3,40 & 3,50 & 3,20 & 3,37 \\
\hline
\end{tabular}

En la Figura 10 se observa como varía el pH de 6,8 a 3,37 en 96 horas 


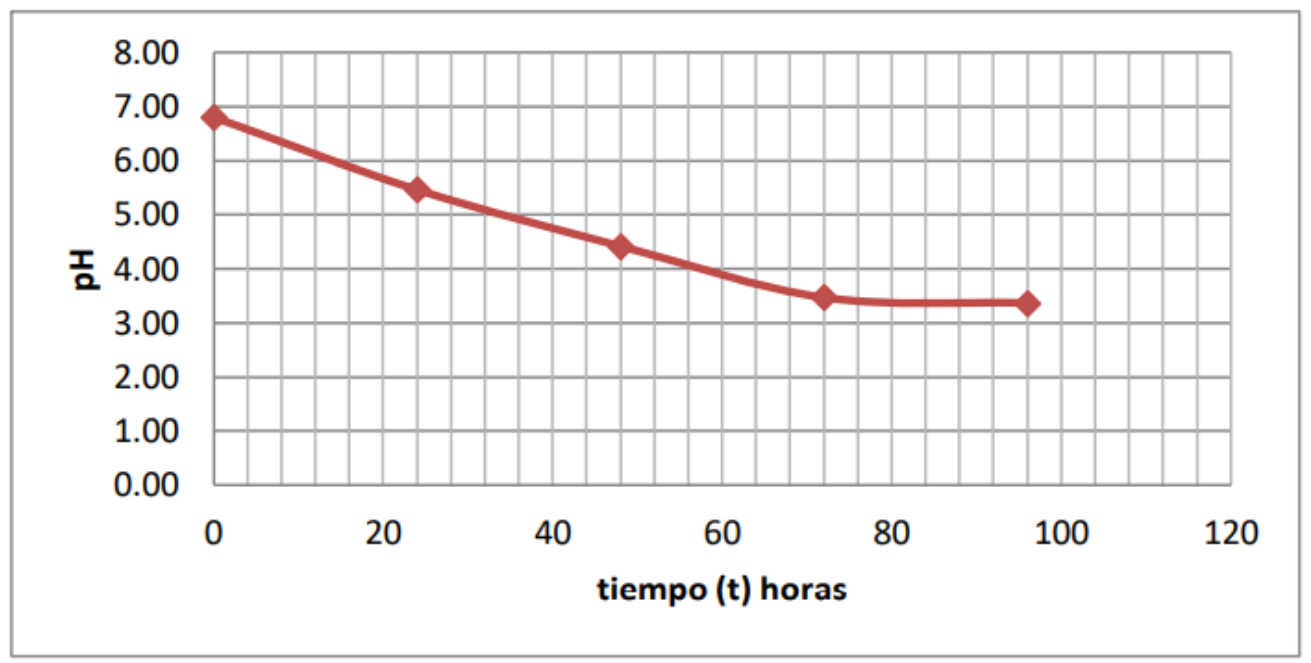

Figura 10. Disminución del pH en función del tiempo (horas) durante el proceso.

\section{DISCUSION}

Los residuos sólidos están conformados por aquellas partes del pez que no poseen un valor comercial, estos son: cabeza, cuero, vísceras, aletas y agallas, los cuales se utilizaron para la elaboración del ensilado, teniendo cuidado en su preservación a fin de evitar contaminación ambiental según recomienda Santos., (2005).

La obtención del ensilado o fermentado de los residuos sólidos del pescado se obtuvieron utilizando los parámetros tecnológicos propuestos por Sosa., (2017), tales como, concentración de sustrato (fuente de carbono) de la melaza, pH, concentración del inóculo (bacterias lácticas) y material a fermentar. (Consumer, 2013).

Siguiendo la recomendación de Consumer., (2013), el tratamiento térmico de los residuos sólidos, haciendo la acotación que la gran mayoría de los investigadores optan por la cocción (temperatura $99^{\circ} \mathrm{C}$ ); sin embargo, en este estudio se utilizó la esterilización (temperatura $115^{\circ} \mathrm{C}$ ), con el objeto de destruir los agentes patógenos esporulados termo resistentes, debido a que estos no son destruidos por una simple cocción.
Las bacterias de lactobacilos del yogurt actúan frente al sustrato convirtiéndolos en ácido láctico y reduciendo el $\mathrm{pH}$, tal como indica también Sosa., (2017).

El uso del modelo logístico, supera al modelo exponencial de primer orden e interpreta mejor los resultados de la cinética de formación de ácido láctico durante el proceso ensilado o fermentación también sustentado por Velázquez C, (2020), el cual permite determinar en forma practica la velocidad máxima del proceso y el tiempo de los procesos como puede apreciarse en la Figura 9.

\section{CONCLUSIONES}

- Se validaron los parámetros tecnológicos durante la experiencia en laboratorio se determinó: concentración de sustrato (melaza:10\%), concentración del inóculo (bacterias lácticas: $3 \%$ ), concentración de residuos sólidos de pescado (87\%), la reducción del pH se observa en los ensayos realizados

- La esterilización (120 min) permitió eliminar bacterias y esporas de agentes patógenos que pudieran hacer competencia a los lactobacilos. 
- Se trabajaron tres muestras de residuos sólidos de las mesas de fileteado (jurel), y por el análisis estadístico DBCA, se determinó que no existen diferencias significativas entre las muestras a un nivel de significancia 0,5\%.

- Se aprecia por análisis de regresión que tres ensayos realizados en procesos de fermentación láctica, obedecen a un modelo logístico.

- Aplicando la primera derivada a la función del modelo logístico se obtuvo la velocidad máxima del proceso, así como el tiempo en que sucede.

- Haciendo la simulación del proceso se obtuvieron resultados que permitieron el diseño de un proceso de fermentación para el caso de residuos sólidos de pescado, usando los microorganismos lácticos empleados en la obtención de un yogurt.

- Normalmente en los procesos de fermentación también llamado ensilados, existe una parte exponencial de generación de ácido láctico, cuyo análisis no se continúa, pero, se aplicó el uso del modelo cinético denominado logístico que interpreta todo el proceso de fermentación, y con lo cual se pudo determinar la velocidad máxima de formación de ácido láctico que según el análisis estuvo dentro de las 20 a 48 horas de ensilado, tiempo estipulado para el estudio.

\section{REFERENCIAS BIBLIOGRAFICAS}

Consumer (2013). El pH de los alimentos y la seguridad alimentaria. Recuperado de https://www.consumer.es/seguridad-alimentaria/el-ph-de-los-alimentos-y-la-seguridad-alimentaria.html

FAO. (2019). Ensilado de pescado. Recuperado de http://www.fao.org/3/i9606es/19606ES.pdf

Gil-Horán (2008). Bio producción de ácido láctico a partir de residuos. Recuperado de: www.redalyc.org > pdf

Santos, C. (2005). Prevenção a poluição industrial: Identificação de oportunidades, análise de benefícios e barreiras (Tese de doutorado). Universidad de São Paulo. São Carlos-Brasil.

Sosa, C. (2017). Elaboración de ensilado biológico a partir de residuos de paiche (Araipaima gigas). Recuperado de: http://repositorio.lamolina.edu.pe/bitstream/handle/ UNALM/3272/sosa-espinoza-carmen-fiorella. pdf? sequence $=1$ \&isAllowed $=y$

Spanopoulos-Hernandez, M (2010). Producción de ensilados biológicos a partir de desechos de pescado, del ahumado de atún aleta amarilla (Thunnus albacares) y del fileteado de tilapia (Oreochromis sp), para la alimentación de especies acuícolas. Revista Mexicana de Ingeniería Química, 9 (2): 167-178 Universidad Autónoma Metropolitana Unidad Iztapalapa Distrito Federal, México

Velázquez C, (2020). La ecuación logística. CIENCIORAMA 2. Recuperado de http://www. cienciorama.unam.mx/a/pdf/468_cienciorama.pdf

\section{CORRESPONDENCIA:}

Dr. Víctor Terry Calderón

victor.terry@ulcb.edu.pe 